\title{
Living Without a Diagnosis: The Parental Experience
}

\author{
Celine Lewis, Heather Skirton, ${ }^{2}$ and Ray Jones ${ }^{2}$
}

Aim: The aim of this study was to explore the parental experiences of raising a child without a diagnosis. Method: Qualitative semistructured interviews were conducted with 14 parents recruited through a large Regional Genetics Centre in the United Kingdom. The interview guide was designed to examine issues such as when and why parents started searching for a diagnosis, whether they were still searching, and what psychosocial issues had arisen as a result of not having a diagnosis. Data were analyzed using the Grounded Theory method. Results: The parental experience can be viewed as a journey, which comprises of two distinct components: the inner, emotional experience, and the outer, sociological experience. Issues that comprise the emotional journey include the realization that there is a problem, the experience of testing, reasons for wanting a diagnosis, the emotional impact, and active coping mechanisms. Social issues include the experience with professionals, the various support networks accessed by parents, and issues such as education and housing. The issue of frustration was one that occurred throughout the journey. Conclusion: Although some of the experiences cited by parents are common to families raising a child with a diagnosed condition, lack of diagnosis adds a layer of complexity.

\section{Introduction}

I T IS ESTIMATED THAT in $30 \%-50 \%$ of cases of children with severe learning disability (Hodgson, 1998; Daily et al., 2000) and $60 \%$ of cases of children with multiple congenital anomalies (Cohen, 1997), it is not possible to provide parents with a certain diagnosis or etiological explanation. The psychological and social implications of raising a child with a known disability are well documented (Carmichael et al., 1999; Fanos and Mackintosh, 1999; Sari et al., 2006; Wiedebusch et al., 2008; Wong and Heriot, 2008), but there are only few studies detailing the psychological and social experience of parenting a child without a diagnosis.

Studies investigating the psychosocial experience of raising a child with a known condition have highlighted a variety of experiences encountered by parents. In a qualitative study investigating the experience of parents of children with Down syndrome, parents expressed anxiety about the future, including whether their children would be able to look after themselves independently in later years (Sari et al., 2006). Parents of children with ataxia telangiectasia were found to experience multiple mourning processes including mourning the loss of the child they thought they had and the child they used to have (Fanos and Mackintosh, 1999). In a study focusing on parents of children with fragile $X$ syndrome, parents felt there was a lack of support from clinicians after they had received a diagnosis (Carmichael et al., 1999), and self- blame, behavioral disengagement, and information seeking were found to be some of the coping mechanisms used by parents of children with cystic fibrosis (Wong and Heriot, 2008) and Turner syndrome (Starke and Moller, 2002).

A review of the literature identified two studies in which the parental experience of diagnostic uncertainty was investigated. In one study (Rosenthal et al., 2001) conducted in the United States, researchers identified six areas in which parents claimed a diagnosis would have an impact. These included providing a label, informing treatment, and enabling social support. Results from a study conducted in Denmark (Graungaard and Skov, 2006) showed that parental satisfaction with the diagnostic process was strongly related to the certainty of the diagnosis and that parents found it difficult coping with an uncertain future. Our review of the literature, however, did not identify any studies conducted in the United Kingdom investigating the experience of parenting a child without a diagnosis.

It is important to investigate this issue from a United Kingdom perspective as differences in healthcare systems across these countries may have an impact on psychosocial outcome for parents. In 1997, the provision of genetic services in the European countries was evaluated by the Concerted Action on Genetic Service in Europe (CAGSE). This evaluation revealed that practices, resources, as well as traditions in the different countries varied considerably. Access to genetic services will also vary. Denmark, like the United Kingdom,

\footnotetext{
${ }^{1}$ Genetic Alliance UK, London, United Kingdom.

${ }^{2}$ Faculty of Health and Social Work, University of Plymouth, Plymouth, United Kingdom.
} 
regulates genetic testing through the national healthcare system, whereas in the United States, it is provided by state and private sector organizations (Godard et al., 2003). Further, across Europe and the United States there exists a diversity of cultures and opinions about a number of issues relevant to genetics, including human reproduction issues and community and individual approaches to the significance of disabilities (Godard et al., 2003).

The aims of this qualitative study were therefore to (1) assess the psychosocial parental impact of having a nondiagnosed child in the United Kingdom, (2) identify whether the psychosocial implications were similar to findings from studies in which parents did have a diagnosis, and (3) identify whether there were any issues that were unique to this situation.

\section{Methods}

This was an exploratory study of parents' feelings and experiences, and therefore, we chose a qualitative method (Pope and Mays, 2006). A Grounded Theory approach enables the researcher to draw appropriate themes from the data and to develop explanatory theories in connection with the topic being studied (Strauss and Corbin, 1998). Ethical approval for the study was obtained from the NHS Ethics Committee.

Participants were recruited through staff at a large Regional Genetics Centre in the United Kingdom. Eligible parents had a child who had been seen at the genetic clinic, but who did not, at the time of recruitment, have a diagnosis of an identified syndrome. To achieve maximum variation in the sample, the inclusion criteria consisted of (1) parents who were still actively searching for a diagnosis and those for whom it was not a priority; (2) children who varied in age; (3) parents of children where the nondiagnosed child was an only child and parents of children where there was more than one child in the family; (4) parents who had a "working diagnosis" (a diagnosis given by the clinician that was socially enabling, but did not provide an etiological explanation) such as autism or bilateral cataract, and parents without; and (5) parents who found out there was an undiagnosed condition during pregnancy and parents who found out after the child was born.

Parents of children considered suitable were invited to participate in the study via a letter that included a participant information sheet. They were asked to return the reply slip if they were interested in participating, and face-to-face interviews were then arranged. All participants stated a preference to be interviewed in their own homes. The interviews were conducted by the lead researcher (C.L.) and permission was given by all interviewees for the interview to be audiotaped. Interviews took place between December 2008 and August 2009 and lasted from $30 \mathrm{~min}$ to $1 \mathrm{~h}$. Recruitment occurred in stages to enable the researcher to identify specific characteristics of potential participants, to recruit purposively.

Consent was recorded in writing before each semistructured interview. Where both parents were available, they were asked whether they would prefer to be interviewed together or separately. All couples preferred to be interviewed together. The interview guide was designed to examine issues including when and why parents started searching for a diagnosis, whether they were still searching for a diagnosis and what information they hoped a diagnosis would provide, and what had been the main issues, both practical and emotional, that had arisen as a result of not having a diagnosis.

Interviews were transcribed by the researcher and data were analyzed using the Grounded Theory method (Strauss and Corbin, 1998). The process of interviewing, coding, and categorizing was fluid and continuous. As analysis of the interviews continued, data were coded into either preexisting codes or new codes. Coding and sorting was done using the qualitative research software NVIVO (QSR International Pty Ltd.) and interview questions were amended to take into account the emerging concepts. Categories were continuously checked and compared against segments of the text (constant comparison) to determine their properties and dimensions. During this process, codes and categories were revised, reorganized, split, or merged. A second researcher also coded and categorized parts of the interviews to ensure trustworthiness of the findings. Any disagreements were discussed and amended. At the point when no new codes or categories were emerging, examination of categories was carried out to identify links and relationships between them (axial coding). Finally, as greater insight was achieved, more theoretical and abstract accounts were developed (selective coding). The results of this analysis, including proposed theoretical explanations about the data and their implications for health service provision, are discussed below. All identifying details have been changed to protect confidentiality.

\section{Results}

\section{Sample characteristics}

The parents of 20 children were invited to participate and parents of 9 children agreed to be interviewed (45\% response rate). During five interviews, both parents were present. In the other four interviews, only the mother was present (in three of these cases the parents had separated), resulting in a total of 14 participants. All participants were living in Southern England. Three mothers had given up work either for financial reasons or because it was too difficult to work and look after their children. Two mothers had recently returned to work because their child had turned five, one mother was working part time, one mother was still on maternity leave, one mother chose not to work, and one worked full time. Of the five fathers involved in the study, all worked full time. The ages of undiagnosed children ranged from 3 months to 9 years. Table 1 shows further characteristics of the parents and affected children, including a range of problems as described by the parents. Many of the children had some form of learning difficulty, but the range of physical manifestations was broad. There was a range of activity level concerning the search for a diagnosis. This ranged from "still persevering with all the different channels" to "no longer actively searching." Even though many of the parents described their children as having "developmental delay," two had been given a working diagnosis to describe their child's condition, in one case this was autism and in the other, bilateral cataracts. Another woman had been told her child had a chromosome translocation; however, because the diagnosis was so rare, she regarded it as a nondiagnosis as there was no prognosis.

The overriding theme that emerged was that the experience of having an undiagnosed child was a "journey" encountered by parents. The journey began with the identification of a medical problem and was still ongoing at the time of the 


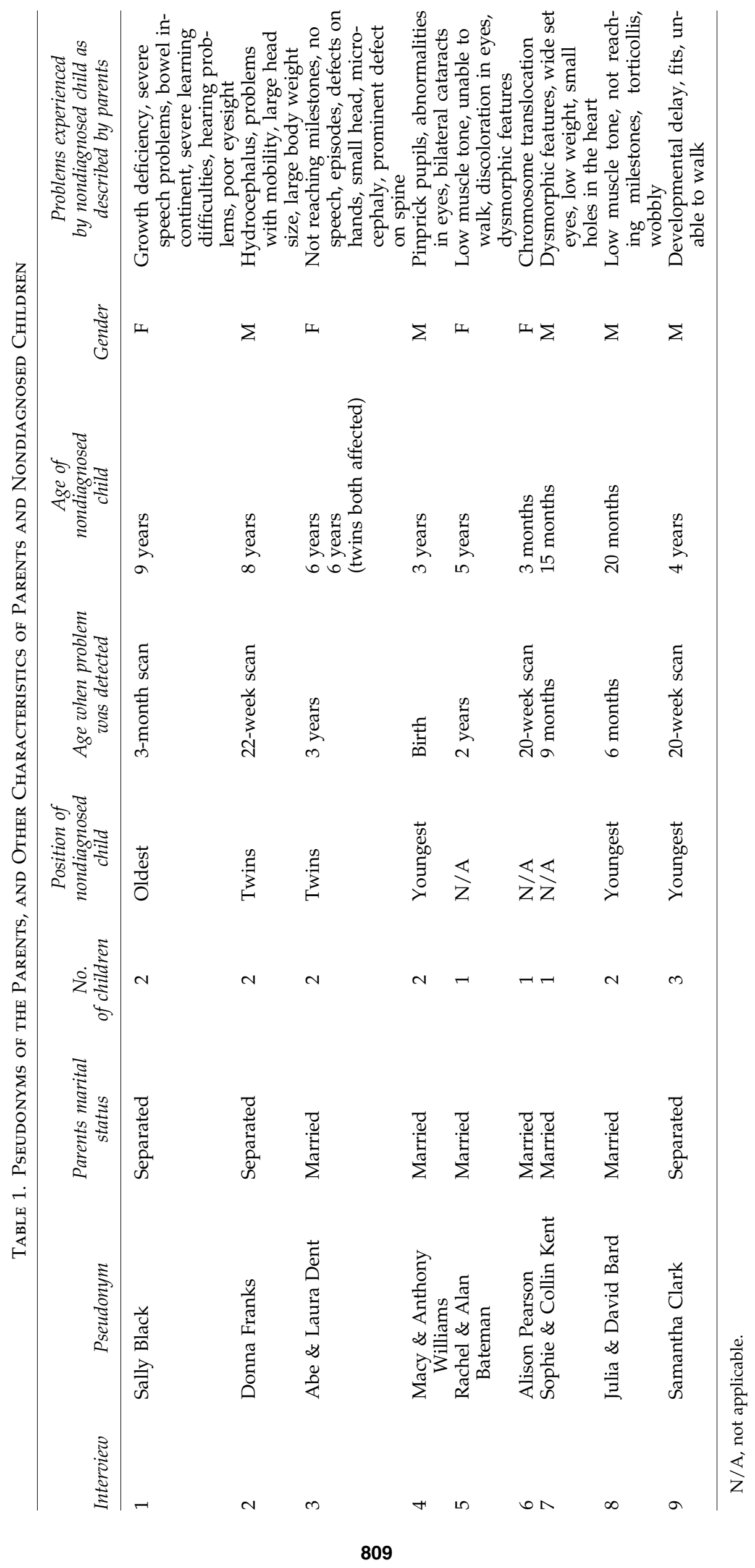


interview. This journey comprises two distinct components: the "inner world" experience, comprising emotions and cognitions, and the "outer world" sociological experience.

\section{The "inner" journey.}

The initial emergence of the problem: There was a noticeable difference in the experiences described by parents depending on whether the problem was identified during pregnancy or not. For those who found out during pregnancy, the information came as a shock and was devastating.

"It was like being hit with a truck. I was sobbing, sitting outside sobbing in the garden and it was awful. It's a real shock because you don't anticipate it. It was horrible, it was really, really horrible." (Alison)

When problems became apparent after birth, the realization that there was a problem was more gradual. It often began when parents started to notice that the child was not reaching certain milestones.

"We realized after six or seven months he wasn't reaching his milestone. He wasn't sitting up, his head in particular, he was always quite floppy." (Julia)

Statements such as "there has been a lot of anxiety" (Macy) and "it was very stressful" (Laura) were used to describe the experience.

Experience of testing: An integral part of the journey was the testing that children underwent during the search for a diagnosis. Most participants named a variety of procedures including blood tests and MRI scans, but other tests such as Xrays were mentioned. Many of the children had undergone testing over prolonged periods. The experience of testing varied for parents. Some were happy for their child to continue testing if it might lead to a diagnosis, whereas for others the experience was traumatic and upsetting. Comments from three parents suggested a certain level of trust with their health professionals.

"If there is an issue and they want to carry on and dig a little further then ok lets just go with it." (Julia)

For other parents, however, the experience was more negative. One had a particularly bad experience because of a number of mistakes being made with blood samples.

"And I think that last time it upset me so much that I said to everyone 'take the bloods you need, store them, and there are no more bloods being taken because I can't put Claire through this'." (Sally)

For those women who were pregnant at the time of testing, the experience was particularly traumatic because it was at a late stage in the pregnancy.

Reasons for wanting a diagnosis: "Help with care and treatment" and "to know about the future" were the two most common reasons given for wanting a diagnosis. Parents felt that if they had a diagnosis it would enable them to make more accurate decisions regarding their child's care and treatment and provide information about the prognosis.

"I'd just like to know how we treat it really. If it's Russell Silver syndrome it can be treated by growth hormones which is a positive thing." (Sophie)

Without a diagnosis, parents were unsure how their child would progress over time, and this was a great source of frustration. One parent described it as being "blind." During three interviews, participants also commented that they wanted a diagnosis just to have "a reason." This desire for a reason implies that having a diagnosis would, for some parents, provide psychological relief, even if it would not change the situation.

“. . . because even if we had a diagnosis he's still Charlie to me, its not going to change him ... its just on a personal emotional level I hate not knowing . ..." (Samantha)

A diagnosis was seen as a social tool by parents of affected children. Three parents raised the point that it would be helpful to have a term that could help summarize what was wrong with their child when asked by friends or other parents.

". . . it would be nice to sort of say oh yes, Laura has got rather than we don't know." (Rachel)

Two mothers explained how they had decided to use the terms "severe special needs" and "developmental delay" to describe their child's condition. This "social diagnosis" made it much easier when asked (by nonmedical people) as it meant they did not have to go into the specific details. One mother had decided upon the term "developmental delay" in a key worker meeting attended by members of her support team (including her health visitor and occupational therapist amongst others). This had been a very useful exercise that she recommended to other parents. Other reasons cited for wanting a diagnosis included concern about recurrent risk in future pregnancies, to help with schooling, and to have an explanation to give to their child.

Feelings about getting a diagnosis: Although parents all said that they would like a diagnosis, when probed further many said that getting a diagnosis was no longer a priority. This was either because they were more concerned with dealing with the day-to-day issues related to the condition, they felt that their child was happy, and therefore, a diagnosis was not vital, or they had come to accept their child's condition and wanted to move on.

"If you worry about having a name for something, if your child is happy and your child isn't in and out of hospital then does it really matter?" (Donna)

Two parents commented that a diagnosis was just a name and would not "change" their child. For one mother, the actual problems, including a hole in the heart, were more important than a name. Three parents mentioned that they would still have to explain what the diagnosis meant to others.

For one woman who had been told her child had a translocation, she still felt that this "diagnosis" did not provide any useful information about the condition or the future.

"So when they told you it was a translocation was that a relief?" (interviewer)

"Well it's like being told something in a foreign language really. It wasn't a relief because I didn't understand it. I'd never heard of a translocation. ... It was still a meaningless diagnosis. You need to know what it means. I don't care what it's called. I just want to know what it means, or what I can do, or what I can do to help." (Alison)

However, for one couple who had been given a working diagnosis of autism while testing was ongoing, the diagnosis was a relief as it proved to others that there was something wrong. Many of their emotional difficulties had been connected with the fact that no one believed there was anything wrong with their children, other than bad behavior. 
"We got a lot of relief out of our diagnosis because at last somebody believed and somebody could see we were not imagining these problems, they were actually there. The girls were actually having difficulties and up until our diagnosis nobody seemed to accept that." (Abe)

Emotional impact: Parents commonly experienced anxiety when they first found out that there was a medical problem, especially if this occurred early in the child's life, before certain possible syndromes could be ruled out. However, most parents did not report feeling anxious over the long term. The emotional issues with a long-term impact related to the lack of control parents felt, particularly regarding their child's future. Issues raised included whether they would have to care for their child for the rest of their lives, whether their child might eventually die from their condition, recurrence risk in future pregnancies, the emotional difficulties of being unable to make "life-plans" for their child, and not knowing how to deal with aspects of their child's development such as the onset of puberty. 6

"I do not know what is going to happen to him in the future and that is the worst thing I think, it is just not knowing because as far as I am concerned I now have to be his carer for the rest of his life." (Donna)

Three participants described their experience as being stressful. Reasons cited included the lack of sleep coupled with a full-time job, the constant visits to hospital, and looking after a special needs child as a single mother. Two parents described the sense of helplessness they felt in trying to find a diagnosis, one father felt that it was "just a case of waiting to see if they do the things that a child with those syndromes would do" (Anthony). A number of parents expressed a sense of guilt relating to their nonaffected children. One woman explained that she felt guilt toward her other child "because we can't go out and do the things that a normal eight-year-old girl would love to be doing" (Donna). Other emotions expressed by parents included the strain on relationships, the lack of psychological help available, and the difficulty in coming to terms with the fact that their child did not look "normal."

However, not all the emotions described by parents were negative in nature. A number of parents commented that the experience was an "emotional rollercoaster." There were "lows," but there were also "highs." For one mother, even though the experience had at times been difficult, it had been "positive overall" (Sophie). Many of the parents were also keen to express how rewarding and loving their child was. Comments including "I love her to death" (Sally) and "he's inspiring sometimes as to how loving and gorgeous he is" (Samantha) were made during the interviews.

Coping mechanisms: The majority of participants used terminology during interviews that implied they were actively coping with their situation and trying to remain positive. Many of these coping statements related to accepting the situation, getting on with life, and just enjoying their children. Parents were also aware of the need to focus their energy on being optimistic, as highlighted by comments such as "you have to keep positive thinking" and "when you focus on the positive your life becomes so much easier." One particular coping mechanism that four parents engaged in was to compare their own situation to others:
“. ...you realize there are children there that are far worse off than Nick. Children with severe cerebral palsy, spina bifida, all sorts of problems...." (Julia)

Father: "It puts it in perspective"

Mother: " . . . and you kind of think, what am I complaining about...." (Julia)

Looking for information, either online or by speaking with other parents, was another coping strategy parents employed. One mother who was given a high risk of Down syndrome after a 20-week scan described how she "spent that weekend talking to colleagues that worked with kinds with Down's, talking to my friend who is a social worker, reading about Down syndrome, getting as informed as I could" (Alison). Another means by which parents coped was by playing an active role in ensuring appropriate care, treatment, and services were met by service providers. Many parents were keen to take control of the situation and, in essence, act as the "gatekeeper" for their child's care. However, there were many examples of parents having to push or fight for services and appointments.

"You have to push, you have to say what's happening and you have to chase people... and you end up getting to a point where you're like 'I don't care if I upset you now, my children matter and you don't' $t^{\prime}$. . I've had to learn to be that sort of person." (Laura)

The sociological journey.

Experience with professionals: Communication and support between medical professionals and parents was on the whole positive, with most parents feeling that there was a good line of communication maintained and support provided. In addition, parents wanted to be active participants in the diagnostic process and felt the medical team acknowledged them as experts on their child's condition, as highlighted by one woman who felt she was free to "ring up and say 'can you check this on the database'." The experience was less positive when it came to communication between health professionals. Two parents found that there was a lack of communication between specialists, and often it was up to them to keep the medical team informed of test results and any specialists seen since the last appointment. A further issue that was particularly frustrating for parents was the need to constantly repeat their child's "life story" because of the numerous different specialists involved in their child's care, and the lack of communication between them.

“. . you are always telling everything again and you just think why can't you just open your notes and read what is in front of you because I have told at least a 100 people this, please I do not want to tell anybody again and this is quite frustrating." (Donna)

The importance of support and advice from professionals such as health visitors, social support workers, and housing officers was evident from interviewees' comments. The health visitor seemed to be a particularly important person along the parental journey, who provided information and support about issues including local nurseries and playgroups, and disability benefits. In some cases the health visitor had adopted a "key worker" role by ensuring all health professionals were kept up-to-date with tests and appointments and by helping facilitate access to services. They also provided psychological support to parents, particularly mothers. 
"Pam my health visitor has been an absolute rock because I mean I've had other problems not just with Charlie but with Leah, his elder sister, eating disorders and things like that. So she has been really involved in my whole family network." (Samantha)

Other specialists who were seen to play an important role included the support worker, the housing officer, and staff at local nurseries and playgroups.

One negative aspect concerning professionals that was mentioned was the high turnover of staff. One woman commented that "You hardly ever see the same person" (Sally). Another parent was also very fearful of the transition to a new team of professionals that would inevitably happen soon, as her son was about to turn 5 years old.

Other support networks: Parents found that having a child with a disability placed a strain on their relationship. One couple found that because they were constantly tired, they rarely went out and spent time together. Two couples acknowledged that they argued more as a result of the stress and worry of looking after a child with special needs. On the whole, parents found that their family members were very supportive; however, there were examples of family members being unsupportive and insensitive. One mother described her sister as treating her son "as a second-class citizen."

Two mothers commented that over the years they had built up a network of friends who also had children with special needs. One mother commented that "you find when you have special needs children most of your friends have got special needs children because they are more understanding" (Laura). She had also found that there was a certain stigma attached to having a child with special needs, and that most of her other friends did not "want to know. You don't get invited to parties or things like that." Parents had made friends through nurseries, schools, and patient support groups.

Support groups, chat forums, and the Internet were further places where parents had found information and support. One father commented that chat forums were good places to retrieve information concerning the important day-to-day issues one might not receive from specialists, and support groups and other charitable organizations helped in some cases by providing respite care and funding equipment and travel. A number of parents, however, commented on the lack of support groups specifically for families without a diagnosis.

Although it was natural for parents to want as much information as possible, many parents spoke of how easy it was to scare yourself while searching for information online. Comments such as "you end up petrified," "it freaks you out," and "I went on line which is a dangerous thing to do" were made about searching on the Internet.

Education, employment, housing, and insurance: Schooling was an important and, sometimes, problematic issue for parents, with some parents unsure whether their child would be better off in a special needs or mainstream school. For two parents, the concept of "dual placement" was particularly appealing, whereby the child spends part of the time in a mainstream school and part of the time in a special needs school. Getting access to appropriate schooling was another hurdle for some parents. The difficulties associated with getting a statement were mentioned during two interviews. The process was so long and laborious for one mother that by the end of it she had "hit rock bottom."

The issue of employment was frequently raised during interviews. For mothers in particular, having a child with a disability had an impact on their ability to work. Five mothers had to give up work as a result of their child's condition, although two had gone back to work as their children had entered full-time education.

"I've tried 2 or 3 times to go back to work but its beaten me in the end and it's like OK I can't do this." (Sally)

One mother found that her son's constant appointments meant it was very difficult for her to commit to an employer. Another had decided to go part time so that she would have the free time needed to take her son to hospital appointments.

A number of participants discussed issues related to housing, particularly the lack of suitable housing made available by the council, which was particularly frustrating for parents. One mother remarked that her council was unwilling to spend money adapting the house because she had no diagnosis.

"He is coming up to 4 now and he is still not walking or anything. The bedroom is upstairs and he is sharing a bedroom with his sister, and they are saying that they won't grant any funds because they say 'well if we do that and spend $£ 50,000$ then in 6 months he might be walking and it will be a waste of money'." (Samantha)

\section{Discussion}

The findings from this analysis highlight the main emotional and social issues that occur throughout the journey undertaken by parents on their search for a diagnosis. This journey can be viewed as a series of waves, or "highs" and "lows." There were the associated difficulties that raising a child with a nondiagnosed condition posed, such as the lack of information about the future and problems in acquiring appropriate housing and education, but there were also positive experiences, such as the supportiveness of professionals and the joy their child had brought to them. This journey, or "emotional rollercoaster" as some parents described it, was a unifying feature of all the experiences documented.

One of the main issues that weaves its way throughout the findings is the issue of frustration. In fact, the issue of frustration was also found to be an issue experienced by parents with undiagnosed syndromes in a similar study conducted in the United States (Rosenthal et al., 2001). Yet, frustration is not an issue experienced only by those without a diagnosis. Other studies have shown that frustration also occurs when parents do have a diagnosis (Russ et al., 2004; Wennick and Hallstrom, 2007; Doig et al., 2009; Henderson et al., 2009). Further, a number of other findings from this study, including the reasons given for wanting a diagnosis, the active role that parents play in managing care and treatment for their child, and the maternal difficulties in meeting employment expectations, were experienced in other studies in which the child did have a diagnosis (Young et al., 2002; Hummelinck and Pollock, 2006; Green, 2007). Yet, there does appear to be one key difference. The difficulties described in studies where parents did have a diagnosis are primarily sociological constraints. However, many of the difficulties in this study are emotional stresses, or as Green (2007) refers to them, "subjective burdens." As well as experiencing sociological burdens, parents in this study ex- 
perienced ongoing psychological issues, particularly the difficulty of coming to terms with not having a reason why, which perpetuated a feeling of being out of control. This emotional distress in particular may make the experience of raising a child without a diagnosis uniquely different.

Parents used a number of different coping methods during their journey. One commonly used was "information seeking," a proactive engagement that is consistent with the "monitoring" style of coping described by Miller (1987). Further, many of the parents in this study took an active role in ensuring their child received appropriate care and support, tried to remain in a positive mindset, and accept the situation [coping behaviors echoed in the findings of Rosenthal et al. (2001)]. These strategies are similar to the "problem-focused coping" and "emotional-focused coping" strategies used by people to cope with a particular situation, as described by Lazarus and Folkman (1984). Parents appeared to use both these strategies, suggesting they were successfully coping with their situation, yet further quantitative research would be needed to test this theory.

Although all parents were still searching for a diagnosis, the importance placed on finding a diagnosis varied, with five parents indicating that for them it was no longer their main priority. Yet, for three parents, the psychological burden of living in a state of uncertainty and the lack of control they had over their situation was very much apparent. These parents appeared to be more motivated to search for certainty, and they had a lower tolerance for ambiguity, a cognitivemotivational factor described in the theory of the need for cognitive closure (Webster and Kruglanski, 1994). However, although the majority of parents who attend genetic services, because their child has learning needs and developmental delay, will be searching for a diagnosis, between 30\% and 50\% do not receive one (Daily et al., 2000). The need for, and lack of certainty, is therefore an issue for many parents seen by genetic specialists. Specialists may, therefore, want to highlight to parents at the beginning of the diagnostic process that a diagnosis is not always achievable if parents do not have unrealistic expectations. It may be helpful, therefore, to discuss other areas where increased certainty may be possible, to give parents an expectation that is more realistic and more likely to be satisfied (Skirton, 2006). Parents should also be reassured that even without a diagnosis, their child should receive care, treatment, and services that are tailored to their needs, and not having a diagnosis should not stop their child from reaching their full potential.

Parents who had found a professional (such as a health visitor) who coordinated care, facilitated access to specific services, and provided emotional and social support found this assistance to be extremely valuable. In addition, their experience was noticeably less traumatic, with fewer instances in which they had to "push" or "fight" for services or appointments. A number of other United Kingdom studies and reports assessing the impact of a key worker have reported similar findings (Liabo et al., 2001; Rahi et al., 2004; Greco et al., 2006; Allford and Hillier, 2008), highlighting the need for and importance of a key worker program for all families of children with disabilities, particularly those with multiple syndromes. In the United Kingdom, studies evaluating the impact of a key worker program found that parents benefited from the important information, especially about education and social services, and emotional support provided by the community link team. Coordinating care and supporting families with care planning and review, speaking on behalf of the family when dealing with services, mediating between schools and families to tackle problems and to resolve sensitive or contentious issues, and providing help and support in a crisis are further areas where the role of the key worker could be expanded. If health visitors are the most appropriate professionals to provide this service, it is important that they receive the appropriate training to enable them to understand service users' needs, provide psychological and informational support, and access relevant services in a timely manner. Further, community health workers exist in many settings, but the background and actual role may differ from country to country or even state to state. The key worker in each case should be the professional who is best placed to be effective and most acceptable to the family, regardless of actual title. A further finding from this study was that without a diagnosis many parents felt there was no appropriate support group to contact. However, a number of organizations in the United Kingdom, such as Unique and Contact a Family, do cater for parents without a diagnosis. Clinicians and health workers need to be aware of these organizations so that they can effectively signpost parents toward them.

Numerous similarities in methods and findings were identified between this study and the Danish (Graungaard and Skov, 2006) and American (Rosenthal et al., 2001) studies. All three were qualitative studies based on semistructured indepth interviews with parents. However, in the Danish study, half the parents did have a diagnosis for their child's condition. Similar reasons for wanting a diagnosis were found in this study and that conducted in the United States. These included wanting information about their child's prognosis and wanting a "label" as a way to help other people understand their child's condition. However, parents in the Rosenthal et al. study seemed more concerned with the issue of reproductive risk than was evident in our findings. This may be attributed to the fact that some of the siblings of the affected children in the American study were at or reaching reproductive age. Parents in all three studies found it emotionally difficult coping with an uncertain future; however, like this study, some of the participants in the study by Rosenthal et al. felt that their interest in a diagnosis had diminished over time. There was an acknowledgment that even with a diagnosis, the situation would not substantially change. Similar to our findings, Rosenthal et al. found that parents had to fight to access services, including services from school districts, therapeutic services, or assistive equipment. This issue was not evident in the Danish study, possibly because this area was not explored or perhaps because services and equipment are more easily accessible and available in Denmark. This is an area that would benefit from further research. Use of problemfocused and emotional-focused coping strategies by parents was evident across all three studies. Like our study, Graungaard and Skov highlighted that parents sought information, learnt new skills, sought social support, and tried to focus on the positive. Similarly, Rosenthal et al. found that parents were active in ensuring their child received appropriate services, wanted as much information as possible, had come to accept the way their child was, and wanted to meet other parents whose children were similar to their own. Interestingly, the term "frustration," a common theme in our findings, 
was also used on a number of occasions by Graungaard and Skov and Rosental et al. to describe the experience of parenting a child without a diagnosis. These findings highlight that even across countries with very different healthcare systems and cultures, many parents living without a diagnosis experience very similar psychological and day-to-day difficulties and challenges.

Parents suggested a number of useful measures that other parents could employ, to minimize the difficulties frequently encountered in accessing services, communicating with health professionals, and remaining positive:

- Be aware of all the services and benefits that are available to you. Ask the professional team around you to provide you with this information.

- Other organizations such as patient support groups, charities, your council's Family Information Service, the Citizens Advice Bureau (CAB), and other parents are also a good source of information.

- Not having a "name" for your child's condition can make it difficult when filling out forms. You find you end up writing "undiagnosed condition." Having a letter from your consultant that explains what this means can be helpful.

- It is a good idea to find a term such as "developmental delay" or "SWAN child" (syndrome without a name) that describes your child's condition. This can be helpful when explaining your child's disability to other people (such as friends and other parents). Ask your healthcare specialists to help you come up with a term that best describes your child's disability.

- Keep a record of your child's progress. Keep a diary; take photos and videos if possible. As well as being a useful record to show to doctors, it can also be comforting to look back and see the progress your child has made.

- Create a "passport" for your child. This can be a series of flashcards that explain things such as what your child can and cannot do, what they like/dislike, any health problems they have, etc. These can be taken to appointments and are a quick way of passing on information about your child.

- Do not compare your child to other children of the same age, or how your other children were at that age, as this can be upsetting. Every child is different.

- Try to enjoy your child. It is easy to focus on all their problems and to forget to enjoy watching them grow up.

The rapid advancements that are currently taking place in genomic medicine and diagnostic testing (Miller et al., 2010) offer hope to those patients who are currently living without a diagnosis. Advances in diagnostic capacity through new technologies such as chromosomal microarrays (which are increasingly being used for genetic testing of individuals with unexplained developmental delay or multiple congenital anomalies) offer much higher diagnostic yields for various types of chromosomal aberrations, with testing techniques more efficient at finding submicroscopic deletions and duplications (Miller et al., 2010). This, in theory, is promising for those currently living without a diagnosis. However, the clinical significance of much of the genomic information derived from these tests is not yet certain. The challenge will lie in ensuring that this technology has clinical utility and patient benefit (Ali-Khan et al., 2009). Further, genetic practitioners will need to determine best practices for effective communication of this genetic information, particularly with respect to incomplete knowledge and diagnostic uncertainty if they are to ensure a service that is useful, informative, and appropriate for patients and families.

\section{Limitations}

The participants in this study were self-selecting, and therefore, these results will not necessarily be a true reflection for all parents of children without a diagnosis. In addition, all the participants were living in Southern England and had been seen by staff at one regional genetics service. Further research is needed to see if the psychosocial experience of parenting a child without a diagnosis differs for parents in different geographical locations across the United Kingdom who access different regional genetic centers, primary care trusts, and local educational authorities. In addition, it would be interesting to explore how ethnic background, socioeconomic factors, and personal coping styles affect the parental experience.

\section{Conclusion}

The findings from this study highlight some of the main psychosocial issues experienced by parents living without a diagnosis. Although a lack of diagnosis may add a further layer of complexity to an already difficult situation, a number of experiences cited are common to families raising a child with a known disability. Genetic professionals may find it useful to highlight that with or without a diagnosis, families still face similar challenges, uncertainties, and joys.

\section{Acknowledgments}

The authors thank all the parents who took the time to participate in this study. The authors are especially grateful to Sally Watts and all the staff at the Regional Genetics Service for helping to identify and contact the families.

\section{Disclosure Statement}

No competing financial interests exist.

\section{References}

Ali-Khan SE, Daar AS, Shuman C, et al. (2009) Whole genome scanning: resolving clinical diagnosis and management amidst complex data. Pediatr Res 66:357-363.

Allford A, Hillier M (2008) The Family Route Map Project. Finding a Way Through the Maze. Genetic Interest Group. www.geneticalliance.org.uk/projects/familyroutemap.htm

Carmichael B, Pembrey M, Turner G, Barnicoat A (1999) Diagnosis of fragile- $X$ syndrome: the experiences of parents. J Intellect Disabil Res 43 (Pt 1):47-53.

Cohen M (1997) The Child with Multiple Birth Defects. Oxford University Press, New York.

Daily DK, Ardinger HH, Holmes GE (2000) Identification and evaluation of mental retardation. Am Fam Physician 61:10591067, 1070.

Doig JL, McLennan JD, Urichuk L (2009) “Jumping through hoops": parents' experiences with seeking respite care for children with special needs. Child Care Health Dev 35: 234-242. 
Fanos JH, Mackintosh MA (1999) Never again joy without sorrow: the effect on parents of a child with ataxia-telangiectasia. Am J Med Genet 87:413-419.

Godard B, Kaariainen H, Kristoffersson U, et al. (2003) Provision of genetic services in Europe: current practices and issues. Eur J Hum Genet 11 Suppl 2:S13-S48.

Graungaard AH, Skov L (2006) Why do we need a diagnosis? A qualitative study of parents' experiences, coping and meeds, when the newborn child is severely disabled. Child Care Health Dev 33:296-307.

Greco V, Sloper P, Webb R, Beecham J (2006) Key worker services for disabled children: the views of staff. Health Soc Care Community 14:445-452.

Green SE (2007) "We're tired, not sad": benefits and burdens of mothering a child with a disability. Soc Sci Med 64:150-163.

Henderson SL, Packman W, Packman S (2009) Psychosocial aspects of patients with Niemann-Pick disease, type B. Am J Med Genet A 149A:2430-2436.

Hodgson SV (1998) The genetics of learning disabilities. Dev Med Child Neurol 40:137-140.

Hummelinck A, Pollock K (2006) Parents' information needs about the treatment of their chronically ill child: a qualitative study. Patient Educ Couns 62:228-234.

Lazarus RS, Folkman S (1984) Stress, Appraisal and Coping. Springer Publishing Co., New York.

Liabo K, MNewman T, Stephens J, Loew K (2001) A review of key worker systems for disabled children and the development of information guides for parents, children and professionals. Office for R \& D for Health and Social Care, Cardiff, United Kingdom.

Miller DT, Adam MP, Aradhya S, et al. (2010) Consensus statement: chromosomal microarray is a first-tier clinical diagnostic test for individuals with developmental disabilities or congenital anomalies. Am J Hum Genet 86:749-764.

Miller SM (1987) Monitoring and blunting: validation of a questionnaire to assess styles of information seeking under threat. J Pers Soc Psychol 52:345-353.

Pope C, Mays N (2006) Qualitative research in health care. Pope C, Mays N (eds). Blackwell Publishing, BMJ Books, Oxford, UK.

Rahi JS, Manaras I, Tuomainen H, Hundt GL (2004) Meeting the needs of parents around the time of diagnosis of disability among their children: evaluation of a novel program for in- formation, support, and liaison by key workers. Pediatrics 114:e477-e482.

Rosenthal ET, Biesecker LG, Biesecker BB (2001) Parental attitudes toward a diagnosis in children with unidentified multiple congenital anomaly syndromes. Am J Med Genet 103:106-114.

Russ SA, Kuo AA, Poulakis Z, et al. (2004) Qualitative analysis of parents' experience with early detection of hearing loss. Arch Dis Child 89:353-358.

Sari HY, Baser G, Turan JM (2006) Experiences of mothers of children with Down syndrome. Paediatr Nurs 18:29-32.

Skirton H (2006) Assessing the need for certainty in users of a clinical genetic health service. J Adv Nurs 55:151-158.

Starke M, Moller A (2002) Parents' needs for knowledge concerning the medical diagnosis of their children. J Child Health Care 6:245-257.

Strauss AL, Corbin J (1998) Basics of qualitative research: techniques \& procedures for developing grounded theory (2nd edition). Sage, Thousand Oaks, CA.

Webster DM, Kruglanski AW (1994) Individual differences in need for cognitive closure. J Pers Soc Psychol 67:1049-1062.

Wennick A, Hallstrom I (2007) Families' lived experience one year after a child was diagnosed with type 1 diabetes. J Adv Nurs 60:299-307.

Wiedebusch S, Pollmann H, Siegmund B, Muthny FA (2008) Quality of life, psychosocial strains and coping in parents of children with haemophilia. Haemophilia 14:1014-1022.

Wong MG, Heriot SA (2008) Parents of children with cystic fibrosis: how they hope, cope and despair. Child Care Health Dev 34:344-354.

Young B, Dixon-Woods M, Findlay M, Heney D (2002) Parenting in a crisis: conceptualising mothers of children with cancer. Soc Sci Med 55:1835-1847.

Address correspondence to: Celine Lewis, M.A.

Genetic Alliance UK

Unit 4D Leroy House 436 Essex Road London N1 3QP

United Kingdom

E-mail: celine@geneticalliance.org.uk 
